\title{
Spatial Econometric Analysis on the Exports-PM2.5 Emissions Nexus: Evidence from the Chinese Smog Provinces
}

\author{
Abdelrahim A. M. Yahia', ${ }^{1,2}$ Zhaohua Li ${ }^{1}$ \\ ${ }^{1}$ School of Economics, Huazhong University of Science and Technology, Wuhan, China \\ ${ }^{2}$ Department of Economics, University of Kassala, Kassala, Sudan \\ Email: abdelrahim2uofk@gmail.com
}

How to cite this paper: Yahia, A.A.M. and Li, Z.H. (2021) Spatial Econometric Analysis on the Exports-PM2.5 Emissions Nexus: Evidence from the Chinese Smog Provinces. Open Access Library Journal, 8: e7358. https://doi.org/10.4236/oalib.1107358

Received: March 26, 2021

Accepted: April 27, 2021

Published: April 30, 2021

Copyright $\odot 2021$ by author(s) and Open Access Library Inc.

This work is licensed under the Creative Commons Attribution International License (CC BY 4.0).

http://creativecommons.org/licenses/by/4.0/ (c) (i) Open Access

\begin{abstract}
The study presents an empirical analysis to investigate the effect of export volume and significant factors on PM2.5 emissions in the highest concentrations of air pollution provinces in China during 1998-2015. This paper proposes a spatial econometric model based on an extended Stochastic Impact by Regression on Population, Affluence, and Technology (STIRPAT) model. The results revealed evidence that spatial spillover effects of PM2.5 emissions exist among major provinces. Provinces in the northeast, south-central China, and north China regions have more potential in reducing PM2.5 emissions. Exports per capita have negative and significant effects on PM2.5 emissions, which revealed that an increase in own-province exports per capita would reduce the PM2.5 concentrations of both own province and the neighboring provinces. Also, the results confirm the existence of an inverted-U shaped Environmental Kuznets Curve (EKC) between PM2.5 emissions and economic growth. Surprisingly, the study doesn't validate the pollution haven hypothesis $(\mathrm{PHH})$. Along a similar line, the empirical evidence has shown that the private vehicle has a significant impact on PM2.5 concentrations, whereas energy intensity exerts a negative effect. Other policy suggestions put forth for policymakers on reducing PM2.5 emissions.
\end{abstract}

\section{Subject Areas}

Economics, Environmental Economics, International Economics

\section{Keywords}

PM2.5 Emission, Exports, STIRPAT Model, Spatial Econometric Panel Model, China 


\section{Introduction}

Extensive evidence has suggested that China is one of the most rapid economic growth countries in the world over the last decade. Meanwhile, air pollution and industrialization with smokestacks problems have become increasingly prominent [1] [2], and recently become increasingly with a rapid increase in industrialization and urbanization [3].

The word "smog" a mixture of smoke and fog trapped beneath a temperature inversion [4], gases, and particulate matter, which produces haze and decreases visibility. Smog is mostly caused by emissions of industrial and vehicular, which responded within high concentrations of fine particles in the atmosphere [5]. Fine particulate matter (PM2.5 emissions) originates primarily from many sources such as severe smog and haze episodes, vehicle exhaust, and road dust, these pollutants decrease the atmospheric visibility by scattering and absorbing ambient light and cause serious harm to ecosystem health, and massive economic losses in many developing countries [6], and threaten the human health [7].

According to the World Health Organization (WHO) [8], "China PM2.5 median equivalent 54, currently, it becomes one of the largest emitters of global emissions, mainly evident by the infamous smog that has happened frequently in many provinces particularly in eastern and northern regions". It's evident that various air pollution problems have emerged in China associated with the expansion of trade such as $\mathrm{CO}_{2}$ emissions, carbon monoxide (CO), and sulfur dioxide $\left(\mathrm{SO}_{2}\right)$. And PM2.5 emissions have become increasingly serious in recent times [9] [10]. After China joined the World Trade Organization (WTO) in 2001, it is exports continued to grow steadily [11] [12]. Moreover, a series of environmental problems have arisen to an unprecedented level affecting seriously the quality of life.

To control air pollution Chinese government has adopted a series of policies deemed to solve the problem, among those policies such as subsidies for use of new energy-efficient cars to decrease automobile exhaust emission, provided PM2.5 real-time air quality monitoring data for the public, in addition to the Act for controlling atmospheric emissions from coal combustion. The control policy measures and prevention of PM2.5 emissions have always been an important task in China due to the repetitive occurrence of pollution. Therefore, to provide a significant research basis for effectively preventing PM2.5 concentrations and reducing air pollution, it is of great theoretical and realistic significance to study the impact of exports on PM2.5 emissions.

Globally, several studies are attempting to investigate the effects of trade on air pollution which is useful in designing an effective climate change program and reducing global emissions in international trade [13]. Research-related interest has recently demonstrated that exports have been an inseparable correlate with air pollution, and the pollutants emitted in China as a result of the production of goods for export to foreign consumption [14] [15]. 
Many existing recent-studies provided evidence for the impact of exports on air pollution, but empirical results are mixed. For example, Xu et al. [15] revealed that exports promoted China's air pollutant emissions. Zhao et al. [16] argued that about $55 \%$ - $62 \%$ of production emissions due to exports and most provinces' exports go to the developed east coast and bordering provinces in China. In addition, Lin [17] found that trade openness had a significant positive effect on increasing air pollution. Recently, Ning et al., [18] verified that the interregional trade played a significant role in spillover and feedback effects relating to emissions, and examined that the emission spillover effect was strong in the border provinces.

In contrast, $\mathrm{Du}$ et al. [19] point out that there is a negative relationship between China's haze pollutant emission and each trading partner. On the other hand, Wang et al. [20] used the multi-regional input-output model to study PM2.5 emissions in China and concluded that the trade of intermediate products increased PM2.5 emissions, whereas the final product trade decreased PM2.5 emissions. Some scholars for instance, [21] [22] analyzed the effects of international trade on the environment through technological change. Their finding that trade openness encourages technology transfers, and improves human capital, and strengthening institutions in developing countries. Several studies had proven that the rapid growth in exports and industrialization among the provinces was the most significant factor that can explain the air pollution status [23] [24] [25]. Regardless of the type of emissions, Prell et al. [26] examined the impact of structural changes in international trade on the environment and found that a country with a higher level of integration has much more pollution. We conclude that the existing studies on the role of international trade on air pollution are inconclusive and have not reached a consensus and still exist some deficiencies.

Along a similar line, many studies have investigated the role of socioeconomic indicators on environmental pollutants by expanded in the Stochastic Impacts by Regression on Population, Affluence, and Technology (STIRPAT) identity by adding some independent variables in the basic model [3] [27], and others by used the spatial econometric approach with extending the STIRPAT model [28] [29]. But Authors do not discuss their results in terms of specification tests of the spatial econometric along the lines developed by [30]. During different historical periods, the spatial effects of exports on PM2.5 emissions in the provinces should not be ignored due to the development stages. However, the recent literature review has not given sufficient attention to these approaches to PM2.5 emissions. Cheng et al. [28] is the only group that has used the expanded STIRPAT model in a spatial approach, in which the authors identify the key factors that influence PM2.5 pollution in China. Their findings are consistent with our study. But they used data from 2001-2012 in the city-level, not provincial level, which raises the concern that their results may be partial. While some studies ignored the role of the spatial effect and correlation of PM2.5 emissions 
between different provinces, our study aims and attempting to fill the gaps.

As a result, the study investigates and detects the spatial autocorrelation of PM2.5 emissions among the highest concentrations of air pollution provinces in China, and depending on previous research, the study provides significant contributions as follows:

First, employ a novel spatial econometric technique, to explore the role of export volume and the important factors that influence PM2.5 concentrations from economic aspects. To the best of our knowledge, the kind of this research has not given sufficient attention in these provinces. Second, more considering for developed and incorporate between the expanded STIRPAT model and spatial econometrics model in PM2.5 emission in this distinguished study; will avoid the bias estimation caused due to use the traditional panel econometric models, such as fixed effects, random effects, GMM method, and co-integration method. Third, although the cities-level data provide observations within the narrowly geographical area in the specific regions. Our study used provincial-level long-term panel data (1998-2015) to avoid the erroneous estimates of the spatial spillover effect and the neglect of the complex links between PM2.5 emissions and economic activities resulting from the lack of data for PM2.5 emission of the city-level before 2013. Furthermore, by using the spatial model, we will explore whether the PM2.5 emissions Kuznets curve (PMKC) exists among the provinces or not.

The remainder of the study is structured as follows: In Section 2 we introduce the methodology including model specification and data sources. While Section 3 provides empirical results and discussion and Section 4 concludes.

\section{Methodology}

\subsection{Model Specification}

As a global issue, PM2.5 emissions have been studied widely from different perspectives. The STIRPAT model is one of the most recent measures that has been developed and applied to explore the influence of anthropogenic factors on air pollution indicators, such as PM2.5 emissions. According to the literature review, the original formulation of the IPAT identity presented by Ehrlich's [31], who first found evidence of the existence of the relationship between population and environment, known as $I=P \cdot F(P)$. Thus, $I$ represent environmental impact, $P$ is the population size, and $F$ is a function that measures per capita impact. Commoner [32] played an essential role in the formulation of the IPAT identity in the algebraic formulation, to address policies related to increasing environmental degradation [33]. Consequently, the IPAT identity has become well-known in 1972, by [34] as follows:

$$
I=P \times A \times T
$$

where, $A$ for affluence, and $T$ for technology.

Recently, several reformations of the IPAT identity had conducted by adding new factors, for instance, [35] [36] [37]. Later, the IPAT model and its all refor- 
mulations was considered to be too simple because it is only a mathematical identity, i.e., it does not allow testing a certain hypothesis, and it does not permit the non-propositional and non-monotonic changes in human indicators. To address these limitations, Dietz and Rosa [38] proposed that the IPAT accounting identity would be recast into a stochastic form labeled STIRPAT model, to allow random errors in the estimation of parameters and provide a testable model to estimate the contributions of anthropogenic factors on greenhouse gas (GHG) and other emissions, they assume that the STIRPAT model will treat the estimated parameters of the original $I=P A T$ identity, which suppose the elasticity coefficients equal 1 , (i.e., $a=b=c=d=e i=1$ ). Their reformulation is:

$$
I=a P^{b} A^{c} T^{d} e
$$

where $I$ is for environmental impact, and $T$ for technology. Furthermore, $a$ is the constant term, $b, c$, and $d$, which are the coefficients for population, affluence, and technology, respectively and e indicate the residual term. This version allows tests of hypotheses regarding other factors than population and affluence that may modify environmental impact. The model can be expressed in logarithmic form as:

$$
\ln (I)=a+b \ln (P)+c \ln (A)+d \ln (T)+e
$$

Thus, the coefficients in Equation (3) can be thought of as elasticities. Therefore, the elasticity coefficient in the STIRPAT model is not always equal to 1, and this is the significant difference between STIRPAT and the IPAT model.

Several studies have built on the STIRPAT model by expanding decomposition to include more terms to capture greater complexity, such as [37] [39] expanded by adding quadratic terms, to assess the relationship between IPAT, ImPACT, and STIRPAT formulations and to discuss an inverted U-shaped EKC. Fan et al. [40] revised the STIRPAT model by incorporating the percentage of the population living (L) in the urban areas and urbanization level (U) in the model. Likewise, Lin et al. [41] developed the model by adding the urbanization level (Ur) and industrialization level (In) and named the STIRPULnAT model.

However, at this stage of the analysis, the authors did not take into consideration whether these additional variables were conceptually compatible with the model or not.

Thus, depending on the existing literature, and to investigate the main driving sources of PM2.5 emissions in the highest air pollution provinces in China, our study included important variables to the extended STIRPAT model, according to the situation of the Chinese provinces.

First, the structure of energy consumption; many scholars had to focus on energy consumption that directly results in PM2.5 emission to explain the fundamental relationship, with this perspective in consideration, China accelerated industrialization with energy consumption in the secondary industry much higher than in other sectors [28]. Furthermore, most energy consumption in China comes from coal, and it is becoming the main energy source with rich re- 
serves and low prices [42]. Therefore, consume a lot of coal will emit large amounts of PM2.5. Thus, the structure of energy consumption has been included in the framework of our model. Because of this, we use the ratio of province coal consumption to total energy consumption to measure the structure of energy consumption.

Second the vehicle population; an increasing number of studies had examined the impact of the vehicles on PM2.5 emission. Studies by [43] [44] revealed that vehicle numbers were an important factor that has significant and positive effects on PM2.5 emissions. Likewise, Huang et al. [44] revealed that automobile exhausts represent the main pollutant comprising fog and haze. Scientific studies have emphasized that the vehicle exhaust emits black carbon, organic hydrocarbons, as well as various kinds of pollutants that are the basic resources of PM2.5 concentrations [45]. China is now in the stage of rapid urbanization and an increase in household income [25]. Therefore, peoples can increase ownership of civil vehicles. Thus, the amount of possession of private vehicles is also important factors that cannot be neglected, we include private vehicles to represent the vehicle population. Additionally, we decomposed affluence into linear and quadratic terms to test whether the EKC hypothesis exists in PM2.5 emissions. The standard model (3) can be generalized to:

$$
\begin{aligned}
\ln \mathrm{PM}_{2.5 i}= & \alpha+\beta_{1} \ln \mathrm{POPD}_{i}+\beta_{2} \ln \mathrm{GDPP}_{i}+\beta_{3}\left(\ln _{\mathrm{GDPP}_{i}}\right)^{2}+\beta_{4} \ln \mathrm{ENI}_{i} \\
& +\beta_{5} \ln \mathrm{EX}_{i}+\beta_{6} \ln \mathrm{SEC}_{i}+\beta_{7} \ln \mathrm{PVEH}_{i}+\varepsilon_{i}
\end{aligned}
$$

where PM2.5 is the fine particulate matter (PM2.5 emissions) of province $i$, POPD is the population density (expressed as the population divided by the area of each province), GDPP is real GDP per capita represent affluence, GDP per capita is commonly used to verify the inverted-U shaped the EKC hypothesis this study seeks to test this hypothesis and its spatial pattern at the provincial level in China, ENI is energy intensity represent technology level, we included energy intensity proxied with total energy consumption divided by total outputs to represent the technology level. EX denotes exports per capita, SEC is the structure of energy consumption, $\mathrm{PVEH}$ is the amount of possession of private vehicles, and $\varepsilon$ is the standard error term.

\subsection{Global Spatial Autocorrelation Model}

The model begins with the global spatial autocorrelation index to explain the degree of spatial correlation among the provinces. For the robustness of our model, the study performs global Moran's I index [46] as follows:

$$
\text { Moran's I }=\frac{\sum_{i=1}^{n} \sum_{j=1}^{n} w_{i j}\left(Y_{i}-\bar{Y}\right)\left(Y_{j}-\bar{Y}\right)}{S^{2} \sum_{i=1}^{n} \sum_{j=1}^{n} w_{i j}}
$$

where $w_{i j}$ represents the spatial weight matrix element to measure the distance between provinces $i$ and $j$, if the provinces have a mutual border the value of the element in the matrix equals 1 otherwise it equals 0 , the term $Y$ denotes the ob- 
servation of PM2.5 emissions and $S^{2}$ is the standard deviation of observation. The values of the global Moran's I index ranges from -1 to 1 . The negative values indicate that air pollution exists negative spatial autocorrelation, while the positive values imply that air pollution exists positive spatial autocorrelation, the values -1 and 1 indicate perfect dispersion and perfect correlation respectively. The zero value means that there is no spatial autocorrelation or random spatial pattern.

Typically, Moran's I index scatter reflects the existence of autocorrelation between observations and the neighbors [47]. The local Moran's I scatter divided into four quadrants. The first and third quadrant reflects the positive autocorrelation, inversely; the second and fourth quadrant denotes negative autocorrelation.

\subsection{Spatial Econometric Models}

Based on the extended STIRPAT model in Equation (4) we will construct the spatial econometric model, by taking into consideration the fact that PM2.5 emissions are heterogeneous and spatially correlated among provinces. Therefore, the study follows the spatial econometric models proposed by [48] which allow describing the spatial correlation base on three basic models.

First, the spatial lag model (SLM), the SLM model aims to explores whether the dependent variable in a specific province is partially determined by a spatially weighted average of neighboring dependent variables [49] [50], this means that PM2.5 emission in province $i$ affected by the surrounding conditions of PM2.5 emission intensity in province $j$. The SLM is formulated as follows:

$$
Y_{i t}=\rho \sum_{j=1}^{N} W_{i j} Y_{j t}+X_{i t} \beta+\mu_{i}+\eta_{t}+\varepsilon_{i t}
$$

where $Y_{i t}$ denotes the dependent variable for the cross-sectional province $i$ at time $t$ (i.e. vector of dependent variables), $X$ is a matrix of explanatory variables, $W_{i j}$ is the element of a spatial weighting matrix, is the $N \times N$ weight matrix, $\rho$ is the scalar spatial autoregressive coefficient, which explores the effects of the spatial factors on the dependent variable, $\beta$ is a column vector parameter and matching with $X_{i}$, the term $\mu$ indicates individual-specific effect for each province, $\eta$ represent a time-period specific effect, $\varepsilon$ is the error term assumed to be $\varepsilon_{i t} \approx N\left(0, \sigma^{2} I\right)$ and the term $\Sigma W_{i j} Y_{j t}$ is the interaction impact of the dependent variable in province $i$ with the dependent variables in the neighboring provinces.

Second is a spatial error model (SEM), in SEM the error term in province $i$ is affected by neighboring error term in province $j$ according to spatial weights matrix $W$ and the random error component, the SEM is expressed as follows:

$$
\begin{aligned}
Y_{i t} & =X_{i t} \beta+\mu_{i}+\eta_{t}+\phi_{i t} \\
\phi_{i t} & =\lambda \sum_{j=1}^{N} W_{i j} \phi_{j t}+\varepsilon_{i t}
\end{aligned}
$$

where $\phi_{i t}$ is the spatially autocorrelated error term, the term $\lambda$ is the spatial au- 
tocorrelation coefficient of the error term.

The third is the spatial Durbin model (SDM), it extends the SLM model including spatial lagged values for both the dependent variable and the explanatory variables:

$$
Y_{i t}=\rho \sum_{j=1}^{N} W_{i j} Y_{j t}+X_{i t} \beta+\sum_{j=1}^{N} W_{i j} X_{i j t} \gamma+\mu_{i}+\eta_{t}+\varepsilon_{i t}
$$

where $\gamma$, like $\beta$, is column vector parameters and matching with the explanatory variables.

\subsection{Estimation Methods and Relevant Tests}

This study primarily focuses on the specification tests outlined by [48], as follows:

Firstly, to examine which type of the model is the best to fits the data, we estimate and test the non-spatial fixed models and will apply the likelihood ratio (LR) test to determine fixed effects, and then test the spatial autocorrelation of the residual error to determine what kind of fixed effect should be included using Lagrange multiplier [51] tests and their robustness [51]. Ordinary least-squares (OLS) are usually used to estimate the traditional mixed panel data models, while LM tests are usually used to produce consistent estimates for spatial autocorrelation of the residual error [52]. Besides the traditional fitting goodness (R2) and LR test, the corrected R2 was also used to test the spatial panel model.

Second: to verify which spatial model is the suitable specification, we will test either the SDM model, the SLM model, or the SEM model according to the values of the Wald test and LR test.

The null hypothesis of Wald test (H0: $\gamma=0$ ) to determine if the SDM model can be simplified to the SLM model or not, against the null hypothesis of LR test (H0: $\gamma+\rho \beta=0$ ) to examines whether if the SDM model can be simplified to the SEM model [30]. Both tests follow a chi-square distribution. If we reject both hypotheses, then the SDM model represents the best fit to the data, and if we accept the first hypothesis suggests, then the SLM model best describes the data. Similarly, accept the second hypothesis indicates that the SEM model best describes the data.

\subsection{Study Area}

The study uses annual data of 21 provinces (from the highest concentrations of air pollution regions in China) which have relatively large PM2.5 emissions on average and unfavorable meteorological conditions for pollution dispersion [53], due to the lack of data Taiwan province, Hong Kong and Macao special administrative regions are not included. The sample selection represents about $68 \%$ of the total Chinese provinces. We depend on the official division method to divide the 21 provinces of China into four regions as follows (Table 1).

Figure 1 presents the spatial characteristics of PM2.5 emissions in our sample provinces, it is clear that the dominant pattern of PM2.5 emissions increases 
Table 1. Distribution of the 21 provinces in China.

\begin{tabular}{cc}
\hline Region & Administrative provinces \\
\hline North China & Beijing, Tianjin, Hebei, Shanxi, Inner Mongolia \\
East China & Shandong, Jiangsu, Anhui, Zhejiang, Fujian, Jiangxi, Shanghai \\
The northeast & Liaoning, Jilin, Heilongjiang \\
South-central China & Guangdong, Guangxi, Hainan, Hubei, Hunan, Henan \\
\hline
\end{tabular}

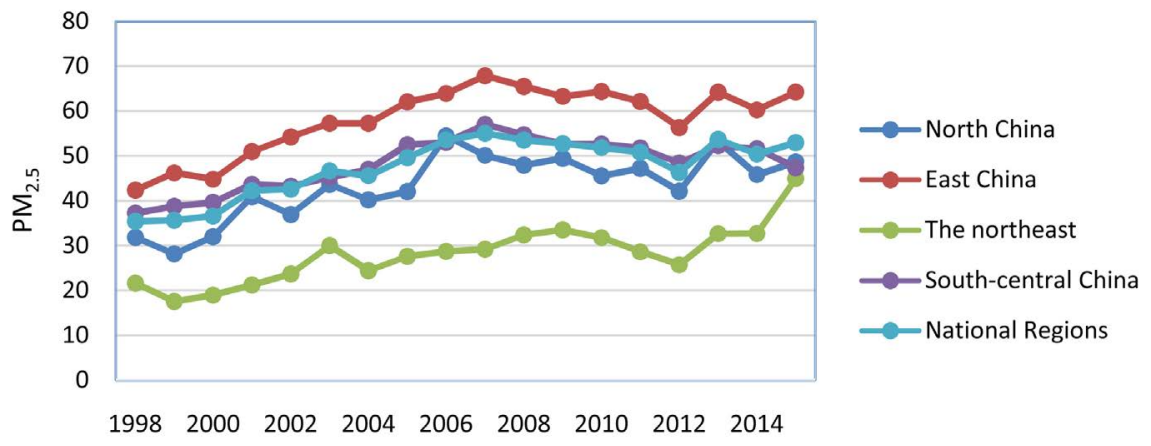

Figure 1. PM2.5 emissions (mean annual) in selected regions in China, 1998-2015.

over time in all regions. With the path of time, the average PM2.5 emissions indices in the east, north and northeast regions present a changing trend fluctuation, but display an increasing trend on the whole, while we can see that south-central China has a downward trend since 2007. The regions such as east China, south-central and north China suffer more serious haze and fog pollution respectively (see Figure 1).

Furthermore, Chinese PM2.5 emissions in overall provinces also present a fluctuating but rising trend, increasing from $35.39 \mathrm{ug} / \mathrm{m}^{3}$ in 1998 in average to $52.95 \mathrm{ug} / \mathrm{m}^{3}$ in 2015 , an average annual growth rate of $2.62 \%$. From a regional point of view, PM2.5 emissions in the eastern region were the highest, with the south-central region the second highest, the emissions of both these regions being higher than the national average. By 2014, the average PM2.5 concentration in the eastern region was $60.23 \mathrm{ug} / \mathrm{m}^{3}$, and the south-central region $51.58 \mathrm{ug} / \mathrm{m}^{3}$, which were 1.72 times and 1.47 times the national second-class concentration limit of PM2.5 (35) respectively. The north region ranked third, while the northeast region had the lowest with the PM2.5 emissions in this region lower than the national average. In 2014, the average concentration of PM2.5 emissions in the north region was $45.81 \mathrm{ug} / \mathrm{m}^{3}$, and the northeast region was 32.71 $\mathrm{ug} / \mathrm{m}^{3}, 1.30$ times and 0.93 times the national second-class limits of PM2.5 (35) respectively.

\subsection{Data Acquisition}

The main variable of interest in the analysis is the PM2.5 emissions, which come from the National Centers for Environmental Prediction/National Center for Atmospheric Research (NCEP/NCAR), we used provincial panel data for 
1998-2015 for 21 provinces in China. The mean value of PM2.5 concentration is $47.50 \mathrm{mg} / \mathrm{m}^{3}$, which exceeded the level of annual PM2.5 standard $\left(35 \mathrm{mg} / \mathrm{m}^{3}\right)$. The overall maximum and minimum also high during this period and highlights the severity of the air quality problem faced by China provinces since the 21 st century.

The annual panel data of the other economic variables such as "Information on population, GDP per capita, energy intensity, exports, coal consumption, and the amount of possession of private vehicles" are collected from China Statistical Yearbook (National Bureau of Statistics of China), and the provincial statistical yearbooks (1998-2015). The definitions of the variables and the basic statistical description of all variables are shown in Table 2.

\section{Empirical Results and Discussions}

\subsection{Spatial Distribution of PM2.5 Emissions in China Provinces}

First, we examine the possible existence of PM2.5 emissions' spatial autocorrelation. According to Equation (5) Table 2 demonstrates the global Moran's I index, the test indicates that the values of global Moran I vary from 0.556 to 0.495 , and PM2.5 emissions display positive spatial autocorrelation at a $1 \%$ significant level, which point out that smog pollution in China exists in an extremely spatial autocorrelation. Furthermore, the overall Moran I over eighteen years is 0.501, which displays also a positive spatial correlation at the same significant level.

The positive values of Moran I indicate that the areas with high PM2.5 emissions (provinces in high-high groups) tend to cluster together, whereas the low PM2.5 emissions intensities, cluster together (provinces in low-low groups) (Table 1 ). These provinces covered by PM2.5 concentration higher than (35 $\mu \mathrm{g} / \mathrm{m}^{3}$ ) were heavily polluted regions (see Figure 1 ). For provincial data, a coincidence of attribute similarity spatial autocorrelation is almost unavoidable, and if ignored like this autocorrelation, it can lead to misleading outcomes [54]. Our results similar to [55] also demonstrated that the economically developed and eastern coastal areas in China with a higher degree of urbanization will suffer more from emissions concentration than others. Therefore, emissions spillover

Table 2. The summary statistical description of the variables.

\begin{tabular}{|c|c|c|c|c|c|c|c|}
\hline Variable & Symbol & Unit & Mean & Std.dev & Min & Max & Observation \\
\hline PM2.5 emission & PM2.5 & $\mu \mathrm{g} / \mathrm{m}^{3}$ & 47.500 & 20.320 & 12.790 & 92.750 & 378 \\
\hline Population density & POPD & People $/ \mathrm{km}^{2}$ & 548.655 & 651.834 & 19.822 & 3825.895 & 378 \\
\hline GDP Per capita & GDPP & Yuan & 42.500 & 37.610 & 4.980 & 173.340 & 378 \\
\hline Energy intensity & ENI & 104 tce & 1.273 & 1.247 & 0.051 & 9.485 & 378 \\
\hline Exports per capita & EXP & Yuan & $7,454,271$ & $1.13 \mathrm{e}+07$ & $99,415.45$ & $5.77 \mathrm{e}+07$ & 378 \\
\hline $\begin{array}{l}\text { Structure of energy } \\
\text { consumption }\end{array}$ & SEC & $\%$ & 0.962 & 0.358 & 0.170 & 2.306 & 378 \\
\hline Private vehicles & PVEH & 104 units & 176.016 & 234.425 & 0.920 & 1351.830 & 378 \\
\hline
\end{tabular}


effects happen due to the imitation of neighbors' economic and environmental policies.

Furthermore, Moran scatter plots were constructed to examine the spatial clustering pattern of emissions. Figure 2 shows that most provinces are located in the first (high-high) and third (low-low) quadrants which indicates the positive spatial autocorrelation.

The result indicates that the provinces in the high-high quadrants have more potential for exporting emission to their neighboring provinces, in contrast, provinces with low-low air pollution "cluster together" with other low polluted provinces.

The number of provinces located in the first and the third quadrants represented about 76\%. While most provinces within the high-high cluster located in the East China region (Shandong, Jiangsu, Anhui), the provinces in the low-low cluster located in the northeast, south-central China, and North China regions such as (Liaoning, Jilin, Heilongjiang, Guangdong, Guangxi, Hainan, Shanxi and Inner Mongolia). Thus, the result implies that global Moran's I exhibit significant spatial autocorrelation and clustering of provincial PM2.5 emissions (see Figure 2).

\subsection{Empirical Results of Econometric Models and Discussion}

To determine which model of those defined in Sections 2.3 fits the data best, and due to the existence of significant spatial autocorrelation as explained above, the study utilizes non-spatial panel model analysis to examine exists of spatial correlation among spatial units using classic Lagrange multiplier [51] tests before building the spatial model for the effect of exports on air pollution. If we reject the non-spatial models, the spatial model should be used to capture the spatiality through the procedures mention in Section 2.4. Table 3 shows the results of the non-spatial models.

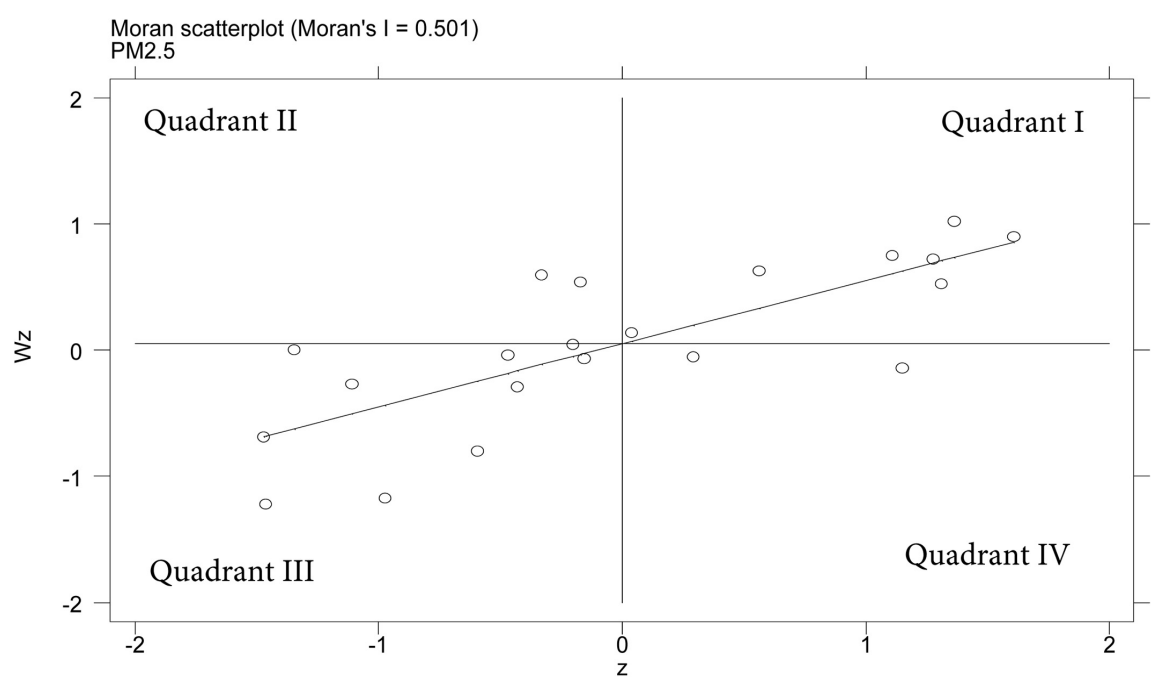

Figure 2. Moran scatter plot of China's provincial PM2.5 emissions (1998-2015). 
Table 3. Estimation results of a non-spatial panel model.

\begin{tabular}{lcccc}
\hline \multicolumn{1}{c}{ Determinants } & Pooled OLS & $\begin{array}{c}\text { Spatial-fixed } \\
\text { effects }\end{array}$ & $\begin{array}{c}\text { Time-fixed } \\
\text { effects }\end{array}$ & $\begin{array}{c}\text { Spatial and } \\
\text { time-fixed effects }\end{array}$ \\
\hline Constant & -1.942 & - & - & - \\
lnPOPD & $0.448^{* * *}$ & $0.915^{* * *}$ & $0.445^{* * *}$ & $-0.384^{* *}$ \\
lnGDPP & 0.889 & $1.748^{* * *}$ & -0.463 & -0.438 \\
lnGDPP2 & -0.0478 & $-0.0878^{* * *}$ & 0.0260 & 0.0128 \\
lnENI & $-0.296^{*}$ & -0.0228 & $-0.461^{* * *}$ & $-0.254^{* * *}$ \\
lnEXP & $-0.0983^{*}$ & 0.0312 & $-0.150^{* * *}$ & $-0.0737^{* * *}$ \\
lnSEC & $0.736^{* * *}$ & 0.0598 & $0.991^{* * *}$ & $0.263^{* * *}$ \\
lnPVEH & $0.111^{* *}$ & 0.0296 & $0.125^{* * *}$ & 0.0313 \\
$\sigma^{2}$ & 0.0646 & 0.0136 & 0.0509 & 0.0078 \\
$R^{2}$ & 0.7137 & 0.5233 & 0.7511 & 0.7553 \\
Adjusted $R^{2}$ & 0.708 & 0.5156 & 0.7471 & 0.723 \\
Log-likelihood & -14.4457 & 279.2063 & 30.1789 & 405.2118 \\
LM spatial lag & $73.9521(0.000)$ & $247.7633(0.000)$ & $46.7125(0.000)$ & $125.5515(0.000)$ \\
Robust LM spatial lag & $61.8106(0.000)$ & $34.4652(0.000)$ & $86.0563(0.000)$ & $15.4379(0.000)$ \\
LM spatial error & $14.1730(0.000)$ & 213.3112 & 0.2866 & $111.7805(0.000)$ \\
Robust LM spatial & 2.0315 & 0.0131 & $39.6303(0.000)$ & 1.6668 \\
error & Time-fixed & 252.0110 & 18 & P-value \\
The joint test of & Spatial-fixed & 750.0659 & 21 & 0.0000 \\
significance LR & Statistics & $\mathrm{df}$ & 0.0000 \\
\hline & & & & \\
\hline
\end{tabular}

Note: The symbols ${ }^{*}{ }^{* *}$, and ${ }^{* * *}$ denotes a significance level of $10 \%, 5 \%$ and $1 \%$ respectively.

To examine the spatial dependence variables, LM tests were employed and its robust tests, all the four kinds of fixed effects support the spatial lag model at a $1 \%$ significance level. Similarly, the error spatial lag LM test and the robust spatial lag LM tests with pooled-effects, spatial, and time-fixed effect and time-fixed effect are significant. Thus, the results reject the hypothesis that spatial correlations do not exist, which confirm exist spatial correlation among the data.

The results of the LR test reject the null hypotheses that spatial fixed effects and time fixed effects do not exist at a $1 \%$ significance level, indicating the significance of introducing spatial dependence items [52], and also justify the extension of the model by including both the space-fixed effects and time-period fixed effects.

To investigate whether the study depends on the SLM model or SEM model instead of the SDM model through performing both the Wald test and the LR test. The results of the Wald test $(33.50$, with 7 -degree freedom, $\mathrm{P}<0.01)$ to determine if the SDM model can be simplified to the SLM model is rejected at a $1 \%$ significance level. Likewise, the results of the LR test (27.10, with 7-degree freedom, $\mathrm{P}<0.01$ ) to explain if the SDM model can be simplified to the SEM model also rejected at the same significance level. Such a finding means the SDM model 
is the convenient specification for this regression.

Furthermore, to determine the best model, we conducted a Hausman test. The estimation results in Table 4, denoted to reject random effects at a $1 \%$ significance level (104.81), indicating that the more appropriate specification model is the model with fixed effects. Table 4 shows that the spatial fixed effects model has the highest goodness-of-fit statistics value (0.6146) and log-likelihood value (439.7567) suggesting that the spatial fixed effects model outperforms the other three models. Therefore, the interpretation will limit on it is coefficients.

The first column in Table 4, shows the coefficient of the spatial lagged term of the dependent variable is positive and significant, this result indicates that PM2.5 emissions in the neighboring provinces have a positive effect on local PM2.5 concentrations. This value is consistent with the outcome of Moran's I

Table 4. Estimation results of the spatial Durbin model.

\begin{tabular}{|c|c|c|c|c|}
\hline Determinants & $\begin{array}{c}\text { Spatial fixed } \\
\text { effects }\end{array}$ & $\begin{array}{l}\text { Time-period } \\
\text { fixed effects }\end{array}$ & $\begin{array}{l}\text { Spatial and } \\
\text { time-period } \\
\text { fixed effects }\end{array}$ & $\begin{array}{c}\text { Spatial random } \\
\text { effects and time } \\
\text { period fixed effects }\end{array}$ \\
\hline $\mathrm{W}^{\star} \ln \mathrm{PM} 2.5$ & $0.762^{* * *}$ & 0.254 & $0.649^{* * *}$ & $0.775^{\star \star *}$ \\
\hline $\ln P O P D$ & 0.037 & $0.312^{\star * *}$ & $-0.281^{\star *}$ & $0.214^{\star * *}$ \\
\hline $\operatorname{lnGDPP}$ & $0.437^{\star \star}$ & 0.489 & -0.1 & $0.797^{\star * *}$ \\
\hline $\operatorname{lnGDPP} 2$ & $-0.0313^{* * *}$ & $-0.0272^{\star}$ & -0.00381 & $-0.0469^{* * *}$ \\
\hline $\operatorname{lnENI}$ & $-0.137^{\star * *}$ & $-0.239^{\star * *}$ & $-0.160^{\star * *}$ & $-0.0873^{\star *}$ \\
\hline $\operatorname{lnEXP}$ & $-0.0422^{\star *}$ & $-0.0707^{\star * *}$ & $-0.0459^{* *}$ & $-0.0335^{\star *}$ \\
\hline $\operatorname{lnSEC}$ & $0.153^{\star *}$ & $0.527^{\star * *}$ & $0.158^{\star \star}$ & $0.113^{*}$ \\
\hline lnPVEH & $0.139^{\star * *}$ & 0.00299 & $0.0943^{* * *}$ & $0.105^{\star * *}$ \\
\hline $\mathrm{W}^{\star} \ln \mathrm{POPD}$ & $0.429^{\star *}$ & $0.216^{\star * *}$ & 0.0698 & -0.01 \\
\hline $\mathrm{W}^{\star} \ln \mathrm{GDPP}$ & 0.302 & $0.199^{* * *}$ & -0.386 & $-0.645^{\star * *}$ \\
\hline $\mathrm{W}^{\star} \ln \mathrm{GDPP} 2$ & -0.00067 & 0.00203 & $0.0353^{*}$ & $0.0467^{\star * *}$ \\
\hline $\mathrm{W}^{\star} \ln \mathrm{ENI}$ & $0.191^{\star *}$ & 0.0278 & $0.169^{\star}$ & $0.237^{\star \star *}$ \\
\hline $\mathrm{W}^{*} \ln \mathrm{EXP}$ & 0.0055 & $-0.209^{\star * *}$ & -0.0536 & -0.00026 \\
\hline $\mathrm{W}^{\star} \ln S E C$ & -0.183 & $-0.211^{\star}$ & $-0.264^{*}$ & $-0.306^{\star * *}$ \\
\hline $\mathrm{W}^{\star} \ln \mathrm{PVEH}$ & $-0.157^{* * *}$ & $0.0533^{\star}$ & $-0.0852^{\star *}$ & $-0.117^{\star * *}$ \\
\hline$\sigma 2$ & $0.00460^{* * *}$ & $0.0287^{\star * *}$ & $0.00388^{\star * *}$ & $0.00498^{\star * *}$ \\
\hline $\mathrm{R} 2$ & 0.6146 & 0.1756 & 0.0658 & 0.5497 \\
\hline \multirow[t]{2}{*}{ Log-likelihood } & 439.7567 & 133.5305 & 486.5581 & 370.7790 \\
\hline & & Statistics & df & $\mathrm{P}$-value \\
\hline \multirow[t]{3}{*}{ Diagnostic tests } & $\begin{array}{c}\text { Hausman } \\
\text { test }\end{array}$ & 104.81 & 15 & 0.0000 \\
\hline & $\begin{array}{l}\text { Wald test } \\
\text { spatial lag }\end{array}$ & 33.50 & 7 & 0.0000 \\
\hline & $\begin{array}{c}\text { LR test } \\
\text { spatial error }\end{array}$ & 27.10 & 7 & 0.0003 \\
\hline
\end{tabular}

Note: The symbols ${ }^{*},{ }^{* *}$, and ${ }^{* * *}$ denotes a significance level of $10 \%, 5 \%$ and $1 \%$ respectively. 
index in Figure 2 and LR tests for spatial autocorrelation in Table 5. The result indicates that for every $1 \%$ increase in the average of PM2.5 emission of neighborhood provinces, the PM2.5 emission of home provinces increases by more than $0.76 \%$ net of other explanatory variables, this coefficient implies that the provinces with similar air pollution emissions generally gather together.

Thus due to the existence of spatial autocorrelation, the estimated coefficients of the independent variables in the SDM model cannot be expressed as marginal effects [48], and cannot accurately reflect the spatial spillover effect of provincial PM2.5 emissions. Therefore, the study depends on the direct, indirect, and total effects to quantify the impacts of explanatory variables and their spatial spillover effect on air pollution.

The results in Table 6 summarize the decomposition estimated direct and indirect effects based on the coefficients of the SDM model in Table 4. The results of direct effects are close to the corresponding regression results of the spatial fixed effects in the SDM model, which explains that the results are steady and effective. But the difference between them in the values of the coefficients estimated due to exit feedback effects which pass through adjacent provinces, and then back to the provinces themselves, which contains two parts; the impacts through the value of a spatially lagged dependent variable $\left(\rho \sum \mathrm{W}^{\star} \ln P M 2.5\right)$ and the other part comes from the coefficients of the spatially lagged independent variables $\left(\sum \mathrm{W}_{\mathrm{ij}} \mathrm{X}_{\mathrm{ity}}\right)$.

With respect to the indirect effects, the results show that only three explanatory variables such as (population density, GDP per capita, and private vehicle) have significant effects, the result indicates that the coefficients estimated of

Table 5. Global Moran's I of PM2.5 emissions in China's 21 provinces, 1998-2015.

\begin{tabular}{ccccc}
\hline & $1998-2000$ & $2001-2005$ & $2006-2010$ & $2011-2015$ \\
\hline Moran's I & $0.556^{\star \star \star}$ & $0.553^{\star \star *}$ & $0.515^{\star \star \star}$ & $0.495^{\star \star *}$ \\
Z-statistic & 3.896 & 3.887 & 3.646 & 3.516 \\
p-Value & 0.000 & 0.000 & 0.000 & 0.000 \\
\hline
\end{tabular}

Note: The symbols ${ }^{*}{ }^{* *}$, and ${ }^{* * *}$ denotes a significance level of $10 \%, 5 \%$ and $1 \%$ respectively.

Table 6. Decomposition estimates of the direct, indirect, and total effects of SDM model.

\begin{tabular}{cccc}
\hline Variables & Direct effects & Indirect effects & Total effects \\
\hline $\ln$ POPD & 0.223 & $1.599^{* *}$ & $1.822^{\star *}$ \\
$\ln$ GDPP & $0.691^{* * *}$ & $2.263^{\star *}$ & $2.954^{\star *}$ \\
$\ln$ GDPP2 & $-0.0408^{* * *}$ & -0.0866 & $-0.127^{\star}$ \\
$\ln \mathrm{ENI}$ & $-0.0991^{*}$ & 0.323 & 0.224 \\
$\ln \mathrm{EXP}$ & $-0.0526^{* *}$ & -0.0973 & -0.150 \\
$\ln \mathrm{SEC}$ & 0.122 & -0.270 & -0.149 \\
$\ln \mathrm{PVEH}$ & $0.116^{* * *}$ & $-0.188^{* *}$ & -0.0726 \\
\hline
\end{tabular}

Note: The symbols ${ }^{*}{ }^{* *}$, and ${ }^{* * *}$ denotes a significance level of $10 \%, 5 \%$ and $1 \%$ respectively. 
these variables in one specific province have a spatial spillover effect on the corresponding factors in the neighboring provinces. Therefore, we can argue that spillover effects exist.

The direct effect of the export variable appears to be -0.0526 with a significant level of $5 \%$, due to the spatial aggregation, while the coefficient estimated by the SDM in the fixed-effects model was -0.0422 . Hence, the feedback effects amount to -0.0104 or 19.8 percent of the direct effect, indicating that the elasticity of exports per capita is underestimated. Moreover, the indirect effect of a change in the export variable in the SDM model seems to be $184.98 \%$ of the direct effect. These results demonstrate that an increase in own-province exports per capita would reduce PM2.5 emissions in their own province and neighboring provinces, hence the relationship between exports and PM2.5 emissions doesn't validate the pollution haven hypothesis ( $\mathrm{PHH})$, which states that high-income per capita countries export their pollution to the lowest countries.

The presented results have shown evidence that exports per capita have a significant negative effect on PM2.5 emissions. In line with previous studies which argued that an improvement in pollution levels with higher exports per capita/the adjustment of export structure and transformation into technology-intensive [56] [57]. Zhang and Tang [58] argue that the reduction of China's emissions mainly depends on the improvement of technical efficiency, whereas export changes will have little effect on emissions reduction. Likewise, the effect of Chinese exports on embodied air pollutants has varied in various sectors [23].

The findings of the study are similar and consistent to those of [10] that has been reviewed earlier, in which the authors examine the effect of trade liberalization on air pollution in 279 Chinese cities. They find that trade is negatively correlated with air pollution. Their findings are consistent with our study. Compared with [10], our results have a greater spillover effect, since we use a larger dataset at the provincial level, but they used city-data.

The findings provide clear evidence that substantiates the relationship between exports per capita and PM2.5 concentrations across the highest air pollution provinces in China.

Therefore, air pollutants in China would be overestimated without considering exports per capita. The difference between our findings concerning the previous studies, the findings are robust in dealing with controls for spatial autocorrelation and provides strong support for the hypothesis that increases in exports per capita will reduce PM2.5 emissions, this might be explained by numerous possible reasons among them.

Firstly, an improvement in the open trade at the province level will lead to improving environmental quality via a decrease of PM2.5 emission, the spatial dependence model indicate an improvement in pollution levels by higher exports per capita. Secondly, in recent, the type of export products of high emission in China gradually changes to low emission and high value-added. In addition, maybe due to China's strict regulations against pollution-intensive in- 
dustries. Third, after entered in the WTO, the Chinese government does not encourage the establishment of high-emission firms; however, to reach international standards it instructed the firms to reduce pollution emissions.

On the other hand, the feedback effect of the population density shows that the population aggregation is a significant factor in local air pollution and has a positive influence on PM2.5 emissions in the neighboring provinces, maybe due to the dramatic expansion of capital cities of the provinces with high population density which will emit more urban pollutants.

The findings also indicate that PM2.5 emission induced by GDP per-capita on both the direct effect and the indirect effect is positive and statistically significant. Furthermore, GDP per capita has the largest positive total effect (2.954) on PM2.5 emission, this result implies that enhancing economic scale is the main influence factor in the model, with positive significant linear and negative signs in the squared term of GDP per capita. The result confirms the existing relationship between PM2.5 emission and economic growth perform an inverted- $\mathrm{U}$ curve of EKC, which is consistent with the study of [43] [59], indicating that, recent smog in China's provinces due to the industrialization and the development stage in China.

Moreover, the estimated coefficient of direct effects of energy intensity is negative and statistically significant at $10 \%$, implying that the effect of a $1 \%$ growth in local energy intensity will reduce $0.0991 \%$ in local PM2.5 emissions. This implies that a province with higher energy intensities tends to have lower PM2.5 emissions. This finding is consistent with Luo et al. [3] who argued that cities in Northwest China and Inner Mongolia provinces have low PM2.5 emissions with high energy intensities. This result also implies that China's technological innovation and the associated increase in energy intensity contribute to reducing PM2.5 concentrations. Thus, as noted above, energy intensity is cleaner than exports per capita.

Furthermore, both the direct effect values and the spillover effects estimation of the structure of energy consumption are insignificantly different from zero, which indicates that a specific province's energy consumption barely affects local and other provinces' emissions. In other words, the coefficient of the structure of energy consumption indicates that a $1 \%$ reduction will lead to a $0.122 \%$ reduction in emission intensity, this means the increase in the ratio of coal consumption to total energy consumption will lead to an increase in PM2.5 concentration. However, the problem with China's power production indicates that the proportion of coal is very high while the proportion of natural gas is very low. When the proportion of coal used in energy production for a long time remained high, this means that consume more coal, and produce large amounts of dust, minute particles, and carbon dioxide which further aggravate urban smog, a finding which is consistent with theoretical expectations and it is supported by many works [43] [50]. Additionally, replacing coal consumption with clean energy sources is an effective mechanism to decrease PM2.5 emissions. 
Similarly, the private vehicle also has a positive impact on PM2.5 concentrations on the direct effect, whereas the coefficient of the spillover effect is negative and significant. This means that own-province private vehicles increases will increase its own PM2.5 emission, but decrease the emission intensity of neighboring provinces. This outcome is consistent with [60]. Thus, increases in the number of vehicles will induce to consume more vehicle fuel, which is reflected in motor vehicle exhaust. The private vehicle in China has risen dramatically, in 2015; the average growth rate of private vehicles owned in Chinese provinces was $12.42 \%$ [11].

\section{Conclusion and Policy Implications}

This study has detected the spatiotemporal variations of export per capita and the main factors that drive the scale and intensity of PM2.5 emissions in the highest concentrations of air pollution provinces in China. The study used spatial econometric methods and extended the STIRPAT model. Based on the above results and discussion, important findings and conclusions are as follows.

The provinces in the northeast, south-central China, and the North China regions have more potential to reduce PM2.5 concentrations than the other provinces, and the Moran I index displays a declining tendency in the sample period indicating that the spatial autocorrelation is strengthened. Therefore, the main way to reduce emissions is by narrowing the difference between the province's emissions. This finding suggests that it is necessary for policy-makers should address provincial differences, and the policies issued should be specific provincial, exactly in the highest emissions provinces to reduce the emissions.

The results show that an increase in own-province exports will lead to reducing the PM2.5 emissions of both own province and neighboring provinces respectively. The results also provided evidence to verify the hypothesis of inverted U-shaped PMKC curves. Although for implementation of the Act for controlling automobile exhaust emission, private vehicles are still an important source of PM2.5 concentrations, therefore, the government should be aware. Thus, in light of these findings, and to move China into the low emissions pathway, policymakers need to adopt policies which aim to reduce PM2.5 emissions.

Firstly, to maintain low levels of PM2.5 emissions, China should continue to extend opening-up policies for trade and change the comparative advantage of the trade-in favor of cleaner production, and promote interprovincial technology cooperation, including both production and emission control technologies. Furthermore, to prohibit the provinces from becoming more emissions in the future, policymakers should implement more strict regulations, such as, imposing more advanced technological processes also will make it possible to suppress pollution emissions and ultimately, to improve environmental quality. On the other hand, readjusting and optimizing industrial structures are the most essential mechanisms for mitigating PM2.5. There would be a notable decline in PM2.5 emissions if the transformations of industrial structures are successful. 
Secondly, it is necessary to optimize, enhancing the energy intensity and, to fully realize its aims to reduce PM2.5 concentrations, Meanwhile, to promote the role of the structure of energy consumption, it is important to increase the use of clean energy use through adjusting the policies of industrial and international trade. Thirdly, China should pay attention more to the excessively rapid growth of private vehicles, particularly in some mega provinces where there are high traffic pressures and enormous air pollution, and to continue in the regulations of the restricted amount of exhaust gas and encourage the use of the new energy and low emission vehicles. To control the excessive growth of private vehicles ownership, the Chinese authorities need to develop urban public transport, and continuous in expand the use of new energy and low-emission vehicles, and should pay more attention to the excessively rapid growth of cars, particularly in several mega cities where there are high traffic pressures and massive air pollutions, in addition to promoting electric taxis and hybrid buses and encouraging green commuting. Finally, low-air pollution technologies and implement policies by the central and provincial governments follow a complementary relationship to control air pollution.

\section{Conflicts of Interest}

The authors declare no conflict of interest.

\section{References}

[1] Hao, Y., Liu, S., Lu, Z.-N., Huang, J. and Zhao, M. (2018) The Impact of Environmental Pollution on Public Health Expenditure: Dynamic Panel Analysis Based on Chinese Provincial Data. Environmental Science and Pollution Research, 25, 18853-18865. https://doi.org/10.1007/s11356-018-2095-y

[2] Michieka, N.M., Fletcher, J. and Burnett, W. (2013) An Empirical Analysis of the Role of China's Exports on $\mathrm{CO}_{2}$ Emissions. Applied energy, 104, 258-267. https://doi.org/10.1016/j.apenergy.2012.10.044

[3] Luo, K., Li, G., Fang, C. and Sun, S. (2018) $\mathrm{PM}_{2.5}$ Mitigation in China: Socioeconomic Determinants of Concentrations and Differential Control Policies. Journal of Environmental Management, 213, 47-55. https://doi.org/10.1016/j.jenvman.2018.02.044

[4] Allaby, M. (2014) Fog, Smog, and Poisoned Rain. Infobase Publishing, New York.

[5] Han, L., Zhou, W., Pickett, S.T.A., Li, W. and Li, L. (2016) An Optimum City Size? The Scaling Relationship for Urban Population and Fine Particulate (PM2.5) Concentration. Environmental Pollution, 208, 96-101. https://doi.org/10.1016/j.envpol.2015.08.039

[6] Agarwal, A.K., Singh, A.P., Lukose, J. and Gupta, T. (2013) Characterization of Exhaust Particulates from Diesel Fueled Homogenous Charge Compression Ignition Combustion Engine. Journal of Aerosol Science, 58, 71-85. https://doi.org/10.1016/j.jaerosci.2012.12.005

[7] Xia, Y., Guan, D., Jiang, X., Peng, L., Schroeder, H. and Zhang, Q. (2016) Assessment of Socioeconomic Costs to China's Air Pollution. Atmospheric Environment, 139, 147-156. https://doi.org/10.1016/j.atmosenv.2016.05.036 
[8] World Health Organization (2016) Ambient Air Pollution: A Global Assessment of Exposure and Burden of Disease. Clean Air Journal, 26. https://doi.org/10.17159/2410-972X/2016/v26n2a4

[9] Warner, K. (2010) Global Environmental Change and Migration: Governance Challenges. Global Environmental Change, 20, 402-413.

https://doi.org/10.1016/j.gloenvcha.2009.12.001

[10] Xu, Y., Fan, X., Zhang, Z. and Zhang, R. (2020) Trade Liberalization and Haze Pollution: Evidence from China. Ecological Indicators, 109, Article No. 105825. https://doi.org/10.1016/j.ecolind.2019.105825

[11] National Bureau of Statistics, China (2018) http://www.stats.gov.cn/english/Statisticaldata/AnnualData/

[12] Yahia, A.A., Li, Z., Ebaidalla, E.M. and He, J. (2021) Exploring the Impact of Exports on Clean Energy Consumption in China: An Empirical Study. Asian Development Policy Review, 9, 44-56. https://doi.org/10.18488/journal.107.2021.91.44.56

[13] Andrew, R., Peters, G.P. and Lennox, J. (2009) Approximation and Regional Aggregation in Multi-Regional Input-Output Analysis for National Carbon Footprint Accounting. Economic Systems Research, 21, 311-335. https://doi.org/10.1080/09535310903541751

[14] Xu, R. and Lin, B. (2017) Why Are There Large Regional Differences in $\mathrm{CO}_{2}$ Emissions? Evidence from China's Manufacturing Industry. Journal of Cleaner Production, 140, 1330-1343. https://doi.org/10.1016/j.jclepro.2016.10.019

[15] Xu, S.-C., Li, Y.-W., Miao, Y.-M., Gao, C., He, Z.-X., et al. (2019) Regional Differences in Nonlinear Impacts of Economic Growth, Export and FDI on Air Pollutants in China Based on Provincial Panel Data. Journal of Cleaner Production, 228, 455-466. https://doi.org/10.1016/j.jclepro.2019.04.327

[16] Zhao, H., Zhang, Q., Huo, H., Lin, J., Liu, Z., Wang, H., et al. (2016) Environment-Economy Tradeoff for Beijing-Tianjin-Hebei's Exports. Applied Energy, 184, 926-935. https://doi.org/10.1016/j.apenergy.2016.04.038

[17] Lin, F. (2017) Trade Openness and Air Pollution: City-Level Empirical Evidence from China. China Economic Review, 45, 78-88. https://doi.org/10.1016/j.chieco.2017.07.001

[18] Ning, Y., Miao, L., Ding, T. and Zhang, B. (2019) Carbon Emission Spillover and Feedback Effects in China Based on a Multiregional Input-Output Model. Resources, Conservation and Recycling, 141, 211-218. https://doi.org/10.1016/j.resconrec.2018.10.022

[19] Du, H., Guo, J., Mao, G., Smith, A.M., Wang, X. and Wang, Y. (2011) $\mathrm{CO}_{2}$ Emissions Embodied in China-US Trade: Input-Output Analysis Based on the Emergy/Dollar Ratio. Energy Policy, 39, 5980-5987. https://doi.org/10.1016/j.enpol.2011.06.060

[20] Wang, Y., Bi, F., Zhang, Z., Zuo, J., Zillante, G., Du, H., et al. (2018) Spatial Production Fragmentation and PM2.5 Related Emissions Transfer through Three Different Trade Patterns within China. Journal of Cleaner Production, 195, 703-720. https://doi.org/10.1016/j.jclepro.2018.05.195

[21] Franco, C., Montresor, S. and Marzetti, G.V. (2011) On Indirect Trade-Related R\&D Spillovers: The “Average Propagation Length” of Foreign R \& D. Structural Change and Economic Dynamics, 22, 227-237. https://doi.org/10.1016/j.strueco.2011.04.003

[22] Seck, A. (2012) International Technology Diffusion and Economic Growth: Ex- 
plaining the Spillover Benefits to Developing Countries. Structural Change and Economic Dynamics, 23, 437-451. https://doi.org/10.1016/j.strueco.2011.01.003

[23] Du, H., Liu, H., Zhu, K. and Zhang, Z. (2020) Re-Examining the Embodied Air Pollutants in Chinese Exports. Journal of Environmental Management, 253, Article ID: 109709. https://doi.org/10.1016/j.jenvman.2019.109709

[24] Meng, J., Liu, J., Guo, S., Huang, Y. and Tao, S. (2016) The Impact of Domestic and Foreign Trade on Energy-Related PM Emissions in Beijing. Applied Energy, 184, 853-862. https://doi.org/10.1016/j.apenergy.2015.09.082

[25] $\mathrm{Xu}, \mathrm{B}$. and Lin, B. (2018) What Cause Large Regional Differences in $\mathrm{PM}_{2.5}$ Pollutions in China? Evidence from Quantile Regression Model. Journal of Cleaner Production, 174, 447-461. https://doi.org/10.1016/j.jclepro.2017.11.008

[26] Prell, C., Sun, L., Feng, K. and Myroniuk, T.W. (2015) Inequalities in Global Trade: A Cross-Country Comparison of Trade Network Position, Economic Wealth, Pollution and Mortality. PLOS ONE, 10, e0144453.

https://doi.org/10.1371/journal.pone.0144453

[27] Ji, X., Yao, Y. and Long, X. (2018) What Causes PM2.5 Pollution? Cross-Economy Empirical Analysis from Socioeconomic Perspective. Energy Policy, 119, 458-472. https://doi.org/10.1016/j.enpol.2018.04.040

[28] Cheng, Z., Li, L. and Liu, J. (2017) Identifying the Spatial Effects and Driving Factors of Urban $\mathrm{PM}_{2.5}$ Pollution in China. Ecological Indicators, 82, 61-75. https://doi.org/10.1016/j.ecolind.2017.06.043

[29] You, W. and Lv, Z. (2018) Spillover Effects of Economic Globalization on $\mathrm{CO}_{2}$ Emissions: A Spatial Panel Approach. Energy Economics, 73, 248-257. https://doi.org/10.1016/j.eneco.2018.05.016

[30] Elhorst, J.P. (2014) Matlab Software for Spatial Panels. International Regional Science Review, 3, 389-405. https://doi.org/10.1177/0160017612452429

[31] Ehrlich, P.R. and Holdren, J.P. (1971) Impact of Population Growth. Science, 171, 1212-1217. https://doi.org/10.1126/science.171.3977.1212

[32] Commoner, B. (1972) The Environmental Cost of Economic Growth. Chemistry in Britain, 8, 52-56.

[33] Chertow, M.R. (2000) The IPAT Equation and Its Variants. Journal of Industrial Ecology, 4, 13-29. https://doi.org/10.1162/10881980052541927

[34] Ehrlich, P.R. and Holdren, J.P. (1972) Critique. Bulletin of the Atomic Scientists, 28, 16-27. https://doi.org/10.1080/00963402.1972.11457930

[35] Schulze, P.C. (2002) I= PBAT. Ecological Economics, 40, 149-150. https://doi.org/10.1016/S0921-8009(01)00249-X

[36] Waggoner, P.E. and Ausubel, J.H. (2002) A Framework for Sustainability Science: A Renovated IPAT Identity. Proceedings of the National Academy of Sciences of the United States of America, 99, 7860-7865. https://doi.org/10.1073/pnas.122235999

[37] York, R., Rosa, E.A. and Dietz, T. (2003) STIRPAT, IPAT and ImPACT: Analytic Tools for Unpacking the Driving Forces of Environmental Impacts. Ecological economics, 46, 351-365. https://doi.org/10.1016/S0921-8009(03)00188-5

[38] Dietz, T. and Rosa, E.A. (1994) Rethinking the Environmental Impacts of Population, Affluence and Technology. Human Ecology Review, 1, 277-300.

[39] York, R., Rosa, E.A. and Dietz, T. (2003) Footprints on the Earth: The Environmental Consequences of Modernity. American Sociological Review, 68, 279-300. https://doi.org/10.2307/1519769 
[40] Fan, Y., Liu, L.-C., Wu, G. and Wei, Y.-M. (2006) Analyzing Impact Factors of $\mathrm{CO}_{2}$ Emissions Using the STIRPAT Model. Environmental Impact Assessment Review, 26, 377-395. https://doi.org/10.1016/j.eiar.2005.11.007

[41] Lin, S., Zhao, D. and Marinova, D. (2009) Analysis of the Environmental Impact of China Based on STIRPAT Model. Environmental Impact Assessment Review, 29, 341-347. https://doi.org/10.1016/j.eiar.2009.01.009

[42] Li, R. and Leung, G.C. (2012) Coal Consumption and Economic Growth in China. Energy Policy, 40, 438-443. https://doi.org/10.1016/j.enpol.2011.10.034

[43] Hao, Y. and Liu, Y.-M. (2016) The Influential Factors of Urban $\mathrm{PM}_{2.5}$ Concentrations in China: A Spatial Econometric Analysis. Journal of Cleaner Production, 112, 1443-1453. https://doi.org/10.1016/j.jclepro.2015.05.005

[44] Huang, R.-J., Zhang, Y., Bozzetti, C., Ho, K.-F., Cao, J.-J., Han, Y., et al. (2014) High Secondary Aerosol Contribution to Particulate Pollution during Haze Events in China. Nature, 514, 218-222. https://doi.org/10.1038/nature13774

[45] Xu, B. and Lin, B. (2016) Regional Differences of Pollution Emissions in China: Contributing Factors and Mitigation Strategies. Journal of Cleaner Production, 112, 1454-1463. https://doi.org/10.1016/j.jclepro.2015.03.067

[46] Moran, P.A. (1950) Notes on Continuous Stochastic Phenomena. Biometrika, 37, 17-23. https://doi.org/10.1093/biomet/37.1-2.17

[47] Anselin, L. (1995) Local Indicators of Spatial Association-LISA. Geographical Analysis, 27, 93-115. https://doi.org/10.1111/j.1538-4632.1995.tb00338.x

[48] Elhorst, J.P. (2014) Spatial Econometrics: from Cross-Sectional Data to Spatial Panels. Springer, Heidelberg, Vol. 479, 480.

https://doi.org/10.1007/978-3-642-40340-8

[49] Kang, Y.-Q., Zhao, T. and Yang, Y.-Y. (2016) Environmental Kuznets Curve for $\mathrm{CO}_{2}$ Emissions in China: A Spatial Panel Data Approach. Ecological Indicators, 63, 231-239. https://doi.org/10.1016/j.ecolind.2015.12.011

[50] Zhao, X., Burnett, J.W. and Fletcher, J.J. (2014) Spatial Analysis of China Province-Level $\mathrm{CO}_{2}$ Emission Intensity. Renewable and Sustainable Energy Reviews, 33, 1-10. https://doi.org/10.1016/j.rser.2014.01.060

[51] Middleton, J.T., Kendrick, J. and Schwalm, H. (1950) Injury to Herbaceous Plants by Smog or Air Pollution. Plant Disease Reporter, 34, 245-252. https://www.cabdirect.org/cabdirect/abstract/19511700576

[52] LeSage, J. and Pace, R.K. (2009) Introduction to Spatial Econometrics. Chapman and Hall/CRC, New York. https://doi.org/10.1201/9781420064254

[53] Wang, Y., Ying, Q., Hu, J. and Zhang, H. (2014) Spatial and Temporal Variations of Six Criteria Air Pollutants in 31 Provincial Capital Cities in China during 2013-2014. Environment International, 73, 413-422. https://doi.org/10.1016/j.envint.2014.08.016

[54] Wei, Y.D., Yu, D. and Chen, X. (2011) Scale, Agglomeration, and Regional Inequality in Provincial China. Tijdschrift voor economische en sociale geografie, 102, 406-425. https://doi.org/10.1111/j.1467-9663.2010.00621.x

[55] Ge, X., Zhou, Z., Zhou, Y., Ye, X. and Liu, S. (2018) A Spatial Panel Data Analysis of Economic Growth, Urbanization, and $\mathrm{NO}_{\mathrm{x}}$ Emissions in China. International Journal of Environmental Research and Public Health, 15, Article No. 725. https://doi.org/10.3390/ijerph15040725

[56] Cole, M.A. (2003) Development, Trade, and the Environment: How Robust Is the Environmental Kuznets Curve? Environment and Development Economics, 8, 
557-580. https://doi.org/10.1017/S1355770X0300305

[57] Tang, X., Jin, Y., Wang, X., Wang, J. and McLellan, B.C. (2017) Will China's Trade Restructuring Reduce $\mathrm{CO}_{2}$ Emissions Embodied in International Exports? Journal of Cleaner Production, 161, 1094-1103.

https://doi.org/10.1016/j.jclepro.2017.05.069

[58] Zhang, Y. and Tang, Z. (2015) Driving Factors of Carbon Embodied in China's Provincial Exports. Energy Economics, 51, 445-454.

https://doi.org/10.1016/j.eneco.2015.08.002

[59] Ma, Y.-R., Ji, Q. and Fan, Y. (2016) Spatial Linkage Analysis of the Impact of Regional Economic Activities on $\mathrm{PM}_{2.5}$ Pollution in China. Journal of Cleaner Production, 139, 1157-1167. https://doi.org/10.1016/j.jclepro.2016.08.152

[60] Dong, K., Hochman, G., Kong, X., Sun, R. and Wang, Z. (2019) Spatial Econometric Analysis of China's $\mathrm{PM}_{10}$ Pollution and Its Influential Factors: Evidence from the Provincial Level. Ecological Indicators, 96, 317-328.

https://doi.org/10.1016/j.ecolind.2018.09.014 